Ambiente \& Água - An Interdisciplinary Journal of Applied Science
ISSN 1980-993X - doi:10.4136/1980-993X
www.ambi-agua.net
E-mail: ambi.agua@gmail.com

\title{
Crise hídrica em publicações científicas: olhares da bioética ambiental
}

\author{
doi:10.4136/ambi-agua.1879 \\ Received: 04 Mar. 2016; Accepted: 27 Apr. 2016 \\ Marta Luciane Fischer; Thiago Rocha da Cunha; Caroline Filla Rosaneli*; \\ Renata Bicudo Molinari; Anor Sganzerla \\ Pontifícia Universidade Católica da Paraná (PUCPR), Curitiba, PR, Brasil \\ Programa de Pós-graduação em Bioética \\ *Autor correspondente: e-mail: caroline.rosaneli@gmail.com, \\ fischer.mrt@gmail.com, caixadothiago@gmail.com, \\ renatabmolinari@hotmail.com, anor.sganzerla@gmail.com
}

\section{RESUMO}

A crise hídrica afeta toda a biodiversidade e dela emergem questões éticas da relação humana com a água e seu impacto nas populações vulneráveis. Este artigo analisa do ponto de vista ético como o meio científico tem abordado a crise hídrica. Analisaram-se produções científicas sobre a crise da água de forma qualitativa pela análise de conteúdo. Identificou-se que o pouco interesse que o meio científico tem em discutir os problemas éticos relacionados à crise hídrica faz com que não se tenha um retrato real de quem são os vulneráveis desse processo. Para superar essa realidade propõe-se a bioética ambiental, com sua metodologia baseada no diálogo interdisciplinar, como a ferramenta capaz de considerar e unir os diferentes interesses sejam humanos ou da natureza, bem como para evidenciar as verdadeiras causas da crise hídrica.

Palavras-chave: água, ambiente, ética, gestão, vulnerabilidade.

\section{The water crisis in scientific publications: environmental bioethics perspectives}

\begin{abstract}
The water crisis affects biodiversity as a whole and creates ethical issues regarding humanity's relationship with water as well as the impact on vulnerable populations.This article analyzes the ethics of the scientific community's approach to addressing the water crisis. Scientific literature relating to the water crisis was analyzed qualitatively based on its content. It was found that the scientific community's reluctance to discuss the ethical problems related to the water crisis results in a failure to clearly identify those who are vulnerable in this process. In order to overcome this failing, we propose the introduction of environmental bioethics, with methodology based on an interdisciplinary dialogue, in order to analyze and integrate the various human or natural interests as well as to highlight the true causes of the water crisis.
\end{abstract}

Keywords: environment, ethic, management, vulnerability, water. 


\section{INTRODUÇÃO}

Na história da humanidade a água sempre foi pensada dentro de uma cultura da abundância, e nesse sentido os problemas éticos limitavam-se a certas regiões que não desfrutavam dessa fartura natural. $\mathrm{Na}$ atualidade, no entanto, a cultura da abundância foi substituída pela da escassez e com isso ampliou-se o universo dos problemas ético-morais a ela relacionados.

Embora esteja intrinsecamente ligada à manutenção metabólica de todos os seres vivos (Jéquier e Constant, 2010) a relação dos humanos com a água varia de acordo com os contextos nos quais o indivíduo está inserido, o que representa que a história, o simbolismo e os rituais em relação à água expressam valores diferentes para cada comunidade. Nesse sentido, o debate da crise hídrica da atualidade vai além da escassez de própria água, pois envolve questões éticas, culturais (ONU, 2012; Castro, 2007), e também problemas relacionados a má gestão pública do recurso, dentro de um modelo econômico que busca resultados imediatistas (Targa e Batista, 2015).

A previsão da Unesco para 2050 é que a população mundial atingirá a marca de 10 bilhões de habitantes. Se mantidas as atuais condições de abastecimento e distribuição de água, $70 \%$ dos habitantes do planeta enfrentarão deficiências no suprimento de água, e um quarto da população viverá em situação de escassez crônica de água potável (Unesco, 2015; Christofidis, 2003).

A chamada crise hídrica tem forçado a humanidade a repensar a sua concepção e relação com a água. Embora a falta d'água tenha despertado mais atenção principalmente por problemas causados nos grandes centros urbanos, no meio rural, o domínio imposto pela política do agronegócio, com sua capacidade política, industrial e econômica sobre a terra, e sua interferência sobre os recursos naturais, tem promovido graves mudanças na biodiversidade e no acesso à água potável.

Do ponto vista simbólico, a exploração desregulada da natureza pelo agronegócio fez com que a água, que no passado se compreendia como o movimento de um líquido vivo que fluía e que pertencia à natureza, que corria e circulava em todas as direções, desse lugar a uma política de represamento da água, para fins econômicos principalmente ligados a irrigação. Essa água parada, por sua vez, deixou de ser sinônimo de vida e passou a ser compreendida como algo impuro, na medida em que a purificação e a renovação da água precisa do movimento e da circulação (Galinozi e Ribeiro, 2011).

Essa prática de represamento e apropriação da água pelo agronegócio, além de comprometer a sustentabilidade ambiental, tem vulnerabilizado os pequenos produtores rurais em sua dignidade e no direito humano à água potável. A relação entre água e direito humano foi reforçada na encíclica "Laudato Si", onde o Papa Francisco afirmou que "o acesso à água potável e segura é um direito humano essencial, fundamental e universal, porque determina a sobrevivência das pessoas e, portanto, é condição para o exercício dos outros direitos humanos" (Papa Francisco, 2015).

A apropriação geográfica da água por represamento também promoveu um forte impacto sobre a cultura dos pequenos produtores rurais, que mantinham laços de repartição e de partilha dos bens da natureza, pois estes eram concebidos como uma dádiva da natureza, portanto, gratuitos e sem preço.

Se a falta de água tem representado uma ameaça à sustentabilidade da vida, ao direito humano e sua dignidade, a complexidade dessa problemática requer o diálogo entre as diferentes áreas do saber, em busca de alternativas em vista à solução do problema. Um documento da Unesco intitulado "A ética do uso da água doce" afirma, neste sentido, que é necessário criar um novo modelo de ciência para o século XXI que esteja "dedicada, motivada pela ética e transdisciplinar, integrando o trabalho dos cientistas sociais, dos economistas e 
dos filósofos morais, ao lado dos cientistas e engenheiros" (Selborne, 2001).

Com base nestes pressupostos que incluem a problemática da crise hídrica como um problema transdisciplinar, global e complexo esta pesquisa analisou do ponto de vista ético como o meio científico tem abordado o tema da crise hídrica, buscando verificar no contexto dessas produções como a bioética ambiental pode servir de instrumento para unir os interesses dos diferentes atores.

\section{MATERIAL E MÉTODOS}

Este estudo parte das bases conceituais propostos por Medina e Pailaquilén (2010), para estudos de revisão sistemática, como opção para não apenas juntar informações, mas acompanhar o movimento científico de um período específico, buscando lacunas e direcionamentos viáveis para a elucidação de temas pertinentes. Para de De-La-Torre-UgarteGuanilo et al. (2011) este método, embora ainda pouco explorado, é útil para as ciências do movimento humano, oferecendo capacidade de síntese e novos direcionamentos.

O levantamento e avaliação da literatura foram realizados em três etapas. Em um primeiro momento foram selecionadas produções científicas a respeito da crise da água publicadas entre 2000 a 2014, a partir da aplicação do marcador "water crisis" no motor de busca do portal Capes Periódicos, ferramenta que congrega as principais bases indexadoras de produção científica, tais como Scopus, ASFA, Scielo, OneFile, Medline, SpringelLink, BioOne, JSTOR e Pubmed. Posteriormente, utilizando-se do mesmo motor de busca foram recuperados os artigos relativos ao termo "water crisis" condicionado ao marcador "ethics". Como este filtro resultou um número reduzido de publicações, por isso, não foi restringida a data de publicação.

Em seguida foi realizada análise exploratória e exclusão de fontes repetidas ou não correspondentes ao tema. Para a categorização utilizou-se a técnica qualitativa de análise de conteúdo (Bardin, 2011). As categorias definidas foram: tipo de documento, abordagem, proposta, causas, responsabilidades, soluções e princípios éticos implícitos.

Os dados do levantamento foram tratados estatisticamente cujo perfil das curvas temporais foi comparado entre si através do teste Kolmogorov-Smirnov. Para a análise do conteúdo dos artigos, a homogeneidade dos valores obtidos para cada categoria definida nos parâmetros causas, responsabilidades e princípios éticos, foi testada através da aplicação do teste goodness-of-fit (Teste G). Em ambas as análises se adotou o índice de confiança de 95\%.

\section{RESULTADOS E DISCUSSÃO}

\subsection{Crise hídrica: publicações científicas entre 2000 e 2014}

O mapeamento dos textos científicos publicados a respeito da crise hídrica entre 2000 e 2014 totalizou 2.899 registros, os quais corresponderam a 47,6\% aos estudos direcionados à água como recurso e suprimento, congregando os temas água potável, subterrânea, rios, aquíferos, absorção e escoamento; $32,1 \%$ dos registros foram relativos ao manejo da água, incluindo temas como questões de sustentabilidade, reservas, dessalinização, reuso e conservação; 6,8\% abordaram questões políticas e econômicas; $5 \%$ discutiram a influência do ambiente, tais como mudanças climáticas e a estiagem; 3,9\% abordaram temas relativos ao impacto da agricultura, irrigação, urbanização e poluição; 3,7\% deram destaque à países específicos como Austrália, China, Índia, Israel e África; e apenas 0,8\% abordaram temáticas como leis das águas, direitos humanos e acordos internacionais.

Temporalmente, foi possível perceber expressivo aumento das publicações após 2007, sobretudo daquelas que abordam as questões de recurso e manejo hídrico (Figura 1). 


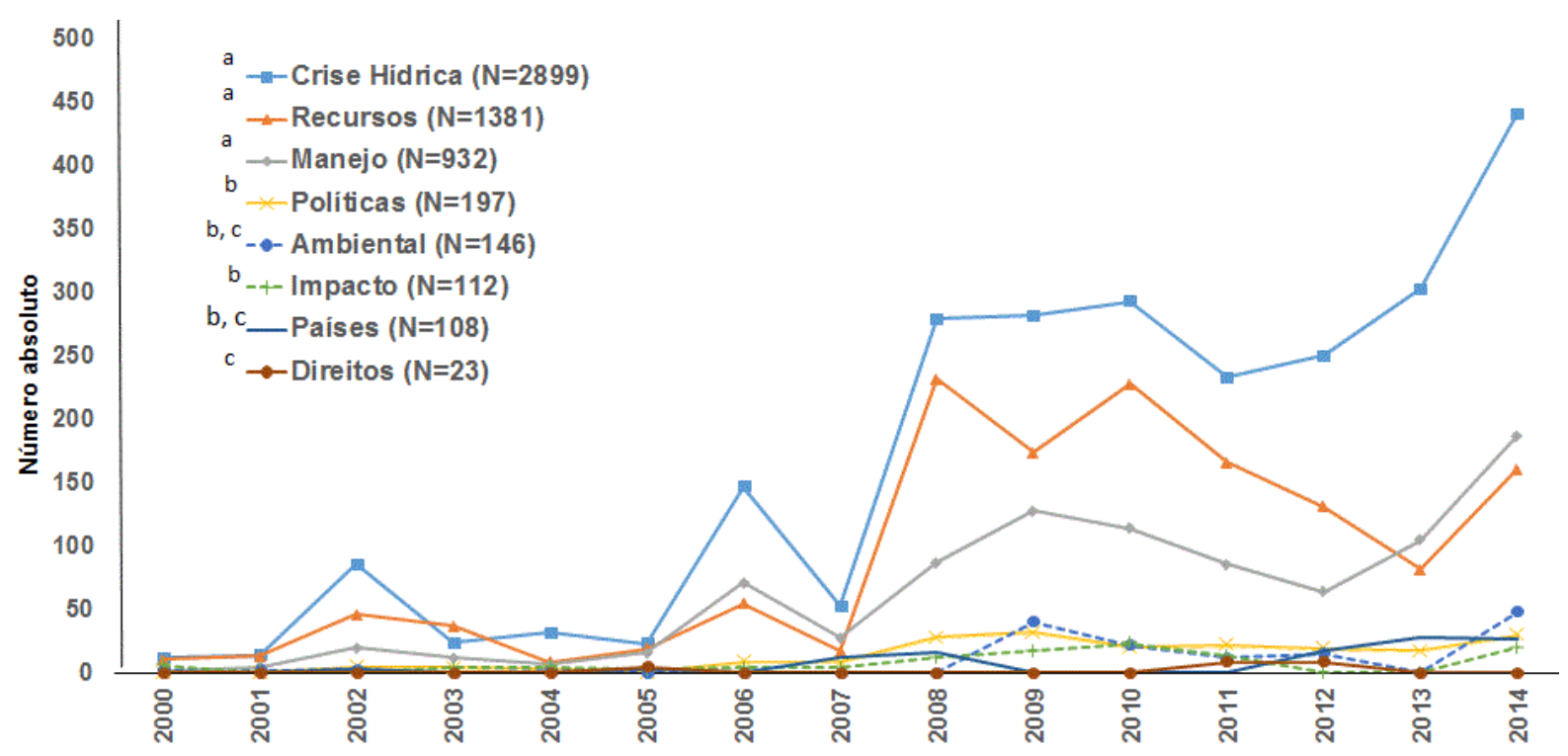

Figura 1. Distribuição temporal das publicações científicas a respeito da crise da água recuperadas no portal Capes Periódicos. Os perfis das curvas foram comparados entre si usando o teste Kolmogorov-Smirnov, sendo as diferenças significativas $(\mathrm{P}<0,05)$ representadas por letras distintas.

Nota: letras semelhantes representam perfis de curvas estatisticamente semelhantes e letras distintas perfis distintos, atestados pelo teste estatístico Kolmogorov-Smirnov.

A análise dos dados mostrou que poucos são os cientistas que tem dado a devida atenção a estudos com aspectos essenciais da problemática da crise hídrica, isto é, dos valores e princípios que norteiam as decisões individuais, e principalmente institucionais na direção das ações. As análises têm priorizado a água como recurso e manejo, sem estabelecer vínculo com os vulneráveis pelo seu uso e necessidade, neste processo.

Para Ren et al. (2013), o investimento em tecnologia e em métodos de mitigação da problemática constitui outro foco de interesse na reflexão da comunidade acadêmica. No entanto, embora se busque respostas práticas ao problema apresentado, esse esforço revela uma postura antropocêntrica, que concebe a água somente como recurso aos humanos, o que revela o caráter paliativo e imediatista desse interesse.

Na visão de Clark e colaboradores, o olhar político e econômico sobre a água limita-se majoritariamente a tratá-la como mercadoria, com a crítica de que ela está disponível somente àqueles que detêm mais recursos econômicos. Essa falta de reflexão sobre a necessidade de proteger a água, e seu acesso em quantidade suficiente para consumo humano e produção de alimentos, se constitui de questões de segurança alimentar que comprometem o bem-estar biopsicossocial dos cidadãos (Clark et al., 2012). A limitação de bases teóricas ou práticas de reflexão dessas abordagens, talvez se constitua um empecilho para alcançar uma solução, do ponto de vista desta análise, mais consensual e justa.

Os dados apontam também para o baixo empenho nas discussões acadêmicas sobre as reais fontes de desperdício ou super utilização do recurso. Sabe-se que o aumento de demanda no sistema agropecuário, sobretudo pelo grande agronegócio de monocultura, é um fator preocupante, além dos óbvios impactos físicos e químicos como poluição e efeito estufa (Eshel et al., 2014).

As curvas temporais das publicações sobre a crise hídrica evidenciaram pelo menos quatros proeminentes picos de produção bibliográfica, em 2002, 2006, 2008-2010 e 2014, sugerindo uma ciclicidade de publicações relativas à crise hídrica que podem sofrer influências de fatores como mudanças climáticas em termos globais, ou mesmo devido ao debate promovido em âmbito mundial através de conferências, fóruns e outros meios que incentivam a criticidade da problemática. 


\section{2. Ética e crise hídrica}

As publicações que apresentaram simultaneamente os marcadores "ethics" e "water crisis" totalizaram 29 textos científicos cuja proposta mais frequente foi a discussão dos aspectos éticos envolvidos na gestão da água potável (69\%) (Tabela 1).

Tabela 1. Propostas dos textos científicos com abordagem ética da crise hídrica.

\begin{tabular}{cl}
\hline Proposta & Fontes \\
\hline
\end{tabular}

Discussão a respeito de aspectos éticos envolvidos na gestão do manejo da água potável

Discussão de aspectos éticos envolvidos no uso da água subterrânea

Discussão a respeito de alternativas para o uso sustentável da água potável

Discussão sobre a crise da água e aspectos, filosóficos, teológicos e culturais
Agoramoorthy (2014); Tvedt (2014); Madani (2014); Schmidt (2014); Yuan et al. (2014); Yazdanpanah et al., (2013a); Ahlert (2013); Ren et al. (2013); Gill (2012); Augusto et al. (2012); Purdy (2009); Berry (2008); Chamberlain (2008); Pontes (2003); Foltz (2002); Freyfogle (1996).

Chinnasamy e Agoramoorthy (2015); Datta (2015); Rahimi et al. (2014).

Clark et al. (2012); Lima et al. (2011); Bakker (2003).

Yazdanpanah et al. (2013b); Bogle (2015); Galizoni e Ribeiro (2011); Reseane (2010); Fiala (2010); Peres (2008); Singh (1992).

As tímidas inciativas científicas com abordagem ética atribuem esta crise hídrica à globalização, à modernidade e aos interesses próprios do mercado, o que evidencia uma reflexão mais focada nos sintomas da crise, do que nas causas (Tabela 2). Essa estratégia, afirma Madani (2014), que busca medidas paliativas, se sustenta por poucos anos, sendo que a somatória dos efeitos colaterais resulta em um quadro pior do que o inicial. Acrescenta Berry (2008) que a crise da água está conectada a um fenômeno ambiental maior e condicionada ao aquecimento global, à desertificação e a perda de biodiversidade. Ren et al. (2013) analisaram a produção científica mundial até 2012 sobre a água, constatando nos últimos anos, temas como "waterrights" e "watermarkets" têm superado temas relacionados às engenharias tradicionais, atestando que a segurança da água é uma estratégia necessária para muitos países.

Os textos científicos de natureza teórica $(75,9 \%)$, por sua vez, apresentaram uma variedade de posicionamentos frente à crise hídrica. Os principais problemas identificados foram relacionados à insegurança hídrica e à agricultura, sendo as principais causas apontadas a globalização, a organização produtiva da modernidade, o mercado e os interesses econômicos (Tabela 2).

As produções científicas tendem a compartilhar a percepção de que a globalização, responsável pela alteração da estrutura biopsicossocial e econômica das sociedades, está na base das causas originais da problemática em todo o mundo. Há uma evidente contradição entre o reconhecimento da água como direito humano e a apropriação deste bem natural pelo mercado, que, ao restringir a disponibilidade e acesso segundo interesses comerciais, contribui tanto para a percepção quanto para a real manutenção da crise. A publicação de 
documentos internacionais nos últimos anos, como a "A ética da água doce" (Selborne, 2001) e mais recentemente a Encíclica "Laudato Si "do Papa Francisco (2015) alertam para o direito humano à água potável e a necessidade urgente de enfrentar os reais problemas para salvaguardar a "nossa casa comum". Chamberlain (2008) afirma que a privatização da água representa um grave crime contra humanidade, o que atenta contra os direitos humanos (Clark et al., 2012).

Tabela 2. Frequência relativa das distintas variáveis relativas às categorias: fontes, abordagens, problemas e causas presentes nos textos científicos analisados sobre a abordagem ética da crise hídrica.

\begin{tabular}{|c|c|c|c|c|c|c|c|}
\hline $\begin{array}{c}\text { Fonte } \\
\left(\mathrm{G}_{\text {test }(3)}=44,\right. \\
8 ; \mathrm{P}<0,01)\end{array}$ & $\%$ & $\begin{array}{l}\text { Abordagem } \\
\left(\mathrm{G}_{\text {test }(2)}=2 ;\right. \\
\mathrm{P}<0,01)\end{array}$ & $\%$ & Problemas NS & $\%$ & $\begin{array}{l}\text { Causas } \\
\left(\mathrm{G}_{\text {test( }(5)}=14,7\right. \\
\mathrm{P}<0,01)\end{array}$ & $\%$ \\
\hline Artigo & $75,9(*)$ & Teórica & $75,9(*)$ & $\begin{array}{l}\text { Insegurança } \\
\text { hídrica }\end{array}$ & 14,5 & $\begin{array}{l}\text { Globalização e } \\
\text { modernidade }\end{array}$ & 33,3 \\
\hline $\begin{array}{l}\text { Resenha } \\
\text { Livro }\end{array}$ & 17,2 & Experimental & 10,3 & Agricultura & 12,9 & $\begin{array}{l}\text { Mercado, interesses } \\
\text { econômicos }\end{array}$ & 23,3 \\
\hline Livro & 3,4 & $\begin{array}{l}\text { Experimental/ } \\
\text { Teórico }\end{array}$ & 13,8 & Urbanização & 9,7 & $\begin{array}{l}\text { Diferenças } \\
\text { socioculturais e } \\
\text { vulnerabilidades }\end{array}$ & 16,7 \\
\hline \multirow[t]{11}{*}{ Tese } & 3,4 & & & Privatização & 9,7 & Água Subterrânea & 10 \\
\hline & & & & Governo & 8,1 & $\begin{array}{l}\text { Perda de } \\
\text { referenciais } \\
\text { culturais e religiosos }\end{array}$ & 3,3 \\
\hline & & & & Poluição & 8,1 & Temperatura Global & 3,3 \\
\hline & & & & $\begin{array}{l}\text { Crescimento } \\
\text { populacional }\end{array}$ & 8,1 & & \\
\hline & & & & $\begin{array}{l}\text { Água } \\
\text { subterrânea }\end{array}$ & 6,5 & & \\
\hline & & & & Reservatórios & 4,8 & & \\
\hline & & & & $\begin{array}{l}\text { Sistema } \\
\text { econômico }\end{array}$ & 4,8 & & \\
\hline & & & & Clima & 4,8 & & \\
\hline & & & & Industria & 3,2 & & \\
\hline & & & & Educação & 3,2 & & \\
\hline & & & & Energia & 1,6 & & \\
\hline
\end{tabular}

"As frequências das variáveis de cada categoria foram comparadas através do $G$ test considerando-se como hipótese nula a existência de homogeneidade, sendo as análises significativas $(\mathrm{P}<0,05)$ acompanhadas pelo valor do teste e, as não significativas, por NS. Os valores significativamente maiores estão acompanhados de asterisco.

A privatização da água e consequente limitação de acesso à mesma, além de gerar graves desigualdades individuais e coletivas, também poderão promover conflitos de proporções inimagináveis. Desde uma perspectiva crítica da bioética, este problema pode ser bem compreendido na tensão entre a "ética capitalista" e a "ética social" identificada por Potter (1999), cujos valores morais que sustentam o capitalismo de livre mercado colocam em risco 
a sobrevivência da humanidade na medida em que "a busca corporativa por lucro máximo exige o crescimento econômico contínuo, mercados em expansão, oferta de trabalho barato ilimitado e crescimento populacional continuado" (Potter, 1999). Trata-se, portanto, de uma política que coloca em risco tanto a estabilidade ecológica do planeta, devido à degradação ambiental, quanto à estabilidade da civilização humana, através dos conflitos resultantes dos processos de exploração e exclusão.

Os textos analisados apontaram como mais relevante à responsabilidade pública na gestão e enfretamento da crise $(81,5 \%)$, como solução a gestão participativa $(32 \%)$ e o balizamento das decisões nos princípios éticos da cooperação e responsabilidade $(23,5 \%)$ (Tabela 3).

Tabela 3. Frequência relativa das distintas variáveis relativas às categorias: responsabilidades, soluções e princípio ético evidente nos textos científicos a abordagem ética da crise hídrica.

\begin{tabular}{|c|c|c|c|c|c|}
\hline $\begin{array}{l}\text { Responsabilidade } \\
\left(\mathrm{G}_{\text {test }(2)}=28,4 ; \mathrm{P}<0,01\right)\end{array}$ & $\%$ & $\begin{array}{c}\text { Soluções } \\
\left(\mathrm{G}_{\text {test }(4)}=8,5 ; \mathrm{P}<0,05\right)\end{array}$ & $\%$ & $\begin{array}{l}\text { Princípios éticos } \\
\left(\mathrm{G}_{\text {test }(5)}=29,4 ; \mathrm{P}<0,05\right)\end{array}$ & $\%$ \\
\hline Responsabilidade pública & $81,5(*)$ & $\begin{array}{l}\text { Transparência na gestão e } \\
\text { participação da população }\end{array}$ & $32,1(*)$ & Cooperação & $23,5(*)$ \\
\hline Responsabilidade Social & 14,8 & $\begin{array}{l}\text { Investimento em infraestrutura } \\
\text { e tecnologia }\end{array}$ & 28,6 & Responsabilidade & $23,5(*)$ \\
\hline \multirow[t]{5}{*}{$\begin{array}{l}\text { Responsabilidade } \\
\text { individual }\end{array}$} & 3,7 & Manejo sustentável da água & 17,9 & Justiça & 17,3 \\
\hline & & Cultura tradicional & 17,9 & Diálogo & 14,8 \\
\hline & & Paliativas e urgentes & 3,6 & Valor à natureza & 13,6 \\
\hline & & & & Proteção e Cuidado & 6,2 \\
\hline & & & & Não Mercantilização & 1,2 \\
\hline
\end{tabular}

*As frequências das variáveis de cada categoria foram comparadas através do G test considerando-se como hipótese nula a existência de homogeneidade, sendo as análises significativas $(\mathrm{P}<0,05)$ acompanhadas pelo valor do teste e as não significativas por NS. Os valores significativamente maiores estão acompanhados de asterisco.

A abordagem científica, em geral, questiona consideravelmente a centralização da gestão hídrica, apontando que enquanto o controle de recursos naturais, essencialmente de valor intrínseco estiver nas mãos do governo, o poder público deverá assumir também toda a responsabilidade de acessibilidade e proteção. Para Purdy (2009), muitas decisões públicas parecem irracionais, e elucidam uma tradição de argumentos políticos sobre natureza a qual simplesmente não traz interesses e valores, que conduzam os cidadãos a entender o seu mundo natural. A necessidade de um novo paradigma no manejo da água, assim como a expansão de um novo olhar para esse bem, é unânime entre os autores pesquisados. Segundo Agoramoorthy (2014), deixar o controle da gestão da água a cargo do governo cria dependência da população e suprime o valor individual para o recurso, além de desempoderar o cidadão em termos de obrigações, decisões e da possibilidade de assumir riscos coletivos.

Abers e colaboradores (2009) que analisaram a crise hídrica sobre a perspectiva da democracia, atributos, opiniões e práticas dos membros de comitês gestores de bacias hidrográficas no Brasil, sugeriram que a prática dos comitês e consórcios são exemplos bem-sucedidos como espaços deliberativos na democracia brasileira. Por isso, é importante considerar o papel da sociedade civil no controle social das políticas hídricas. Autores como Finkler et al. (2015) e Empinotti e Jacobi (2013) discutem como envolver toda a sociedade na 
tomada de decisões, principalmente, em relação ao destino dos recursos financeiros arrecadados e que contribuirão para a compreensão de como a água pode potencializar a construção de práticas de governança que, futuramente, possam regular o uso ético da água.

Segundo Targa e Batista (2015), o planejamento de longo prazo da gestão da água faz-se necessário, a fim de assegurar a disponibilidade de água e energia para consumo humano e de animais, para agricultura e indústria.

A efetividade da gestão dos recursos hídricos relaciona-se com múltiplos processos do uso do solo por atividades para finalidades humana, pois abriga importantes usuários, como as empresas do agronegócio, agricultores de ampla escala, agricultores familiares ou outros agentes que utilizam a água no meio rural. Neste contexto, esta dificuldade ganha em complexidade, pois é no meio rural que o uso e ocupação do solo causam impactos diretos sobre mananciais de abastecimento humano, comprometendo sua disponibilidade quali e quantitativamente (Chiodi et al., 2013).

A responsabilidade da agricultura, particularmente do grande agronegócio, na crise hídrica foi unanimidade nos textos científicos analisados, seja através da produção de alimentos, no desperdício na irrigação, no comprometimento com as fontes de água subterrânea, pela contaminação por pesticida, pela perda de biodiversidade, erosão e assoreamento.

As poucas abordagens científicas pioneiras na discussão de aspectos éticos na crise hídrica reivindicam que condutas e técnicas sustentáveis sejam introduzidas no setor (Chinnasamy e Agoramoorthy, 2015; Rahimi et al., 2014; Ren et al., 2013). Contudo, a maioria dessas pesquisas não identifica o meio rural como vulneráveis diante do impositivo mercado do agronegócio, além das imprevisibilidades naturais como regime de chuvas, estiagem e efeito estufa (Reseane, 2010).

Autores como Yazdanpanah et al. (2013b) e Galizoni e Ribeiro (2011) defendem a ideia de que devem ser resgatados paradigmas tradicionais envolvidos com a cultura, religião e técnicas de produção, os quais eram trabalhados conjuntamente, para superar momentos de crises ou viabilizar a adaptação humana em ambientes historicamente hostis, ou com dificuldade de acessibilidade das redes de distribuição. Logo, as comunidades tradicionais não podem ser negligenciadas em detrimento do público urbano. Segundo Galizoni e Ribeiro (2011), embora os principais consumidores se interessem pela gestão dos grandes corpos d'água, deve-se ater ao fato que estes são abastecidos pelas nascentes que estão sob gestão comunitária.

Assim, processos de gestão aparentemente desconexos estão na base dos embates pelo controle dos mananciais. Âs famílias e as comunidades de agricultores têm sido impostos os custos e penalidades da conservação das águas - assim como restrições ao uso dos solos e florestas - sem que se aprenda com eles os princípios que, ao longo da história, construíram sistemas de partilha quase sempre justos (Gutiérrez-Malaxechebarría, 2014). Para Saldi e Petz (2015), o processo de alienação d'água e da terra pelo homem conduz a um controle pelo Estado. Madani (2014) reforça a existência de marginalização do setor, no qual a falta de incentivos, principalmente para pequenos produtores que se vêm vulneráveis diante da tecnologia e subsídios fiscais direcionados para grandes empresas, acabam por incentivar a migração para centros urbanos, aumentando tanto as demandas de água, quanto impactando nas atividades agronômicas do entorno.

$\mathrm{O}$ acesso às informações qualificadas sobre a água é fundamental (Pontes, 2003), pois somente consciente dessa realidade é possível avaliar os serviços de abastecimento, o uso da água potável na agricultura e indústria, o custo da extração da água subterrânea e os benefícios da irrigação quando comparados com outras utilizações da água consideradas como supérfluas, tais como o resfriamento de equipamentos industriais. Nesse sentido, a água deve ser debatida também como um problema ético, no seu uso sustentável na agricultura, na 
segurança alimentar, na proteção da água para a saúde e saneamento. Passando ser a meta a construção de processos participativos para que as políticas públicas visem à construção de consensos fundamentados em argumentos sociais, científicos, tecnológicos e espirituais (Datta, 2015; Ahlert, 2013; Castro, 2007).

Diante da dificuldade de que as regulamentações possam interessar os consumidores em curto prazo, Fiala (2010), propõe criar incentivos para alternativas verdes e desincentivos para atividades que causem danos ambientais. Segundo o autor a ação voluntária é insuficiente, sendo necessária ação coletiva, de modo a estimular esperança na ação individual e reformar a coletiva, por meio da inspiração das pessoas para olhar além dos próprios interesses e desenvolver o altruísmo.

A participação popular nas decisões relativas à gestão da água, é defendida por Foltz (2002), Yazdanpanah et al. (2013a) e também por Datta (2015). Segundo Foltz (2002), o próprio crescimento populacional e as ambições industriais levarão os governos em algum momento a tomar decisões mais ecológicas e coerentes com os contrastes impostos pelo clima. Contudo, os governos precisam optar se irão aderir às políticas internacionais ou se irão considerar as particularidades da cultura e do clima e programar ações viáveis e sustentáveis de manejo. Segundo Datta (2015) e Ahlert (2013), a superação da crise só ocorrerá através da redução da distância e aumento da sinergia entre cientistas, engenheiros, corpo político e administrativo, os meios de comunicação e a comunidade em geral, afim de que todos os envolvidos se comprometam e busquem conjuntamente uma estratégia de planejamento, de conservação, de investimentos científicos e de inovação, que permitam encontrar alternativas reais e temporais para a crise hídrica.

Uma gestão colaborativa, transparente, intermediada pelo governo, porém, com o empoderamento da participação popular, para a tomada de decisões quanto a mobilização de recursos de infraestrutura e tecnologia, distribuição prioritária e valores necessários para o saneamento, são apontados como as alternativas de solução da crise hídrica por Ahlert (2013), Augusto et al. (2012), Peres (2008) e Foltz (2002). Augusto et al. (2012) também apoiam a necessidade de um modelo de gestão intersetorial com participação da sociedade civil organizada nas concessionárias de saneamento e saúde, a fim de, prevenir desafios com aquecimento global, crescimento populacional e econômico.

Para viabilizar tais ações é fundamental investir na requalificação do quadro técnico com especialistas das ciências sociais e humanas competentes em questão de ética aplicada, que logrem aplicar técnicas apropriadas para gestão de conhecimento da realidade e relacionamento cotidiano com as populações, resultando em avanços significativos para a mobilização da sociedade e de organismos internacionais. E desta forma, criar uma nova comunidade democrática, através da informação e sensibilização hábil em refletir sobre fatos do passado (Purdy, 2009), e projetar soluções realistas e eficientes no presente, bem como tomar medidas de precaução quanto ao futuro (Jonas, 2006).

As decisões não podem ser pensadas unicamente pelo viés da política local e momentânea, pois esta reduz o poder e cria o conflito, afirma Schmidt (2014). É importante sensibilizar a população para que sua colaboração seja percebida muito além do tempo imediato, e sim como uma política global. A construção de uma visão cooperativa, participativa e solidária através do diálogo transparente, que busca a aplicação da justiça é o ponto chave nas discussões éticas da crise hídrica. Para Fiala (2010) é preciso desenvolver a percepção da crise para estimular o desejo voluntário de contribuir. Porém, deve-se considerar que a percepção é condicionada ao interesse próprio, o que tornará a crise insolúvel se o interesse for estritamente racional e em curto prazo. Bakker (2003) ressalta que a conservação do recurso é mais efetivamente promovida através de uma ética coletivista de solidariedade, à qual poderá encorajar usuários a refinar seu comportamento.

Os textos científicos analisados priorizaram como balizador das decisões éticas o 
princípio da responsabilidade, acrescido ao princípio da cooperação. Partindo-se da premissa que a gestão da água envolve pressupostos culturais de relação de poder, gerador de desigualdades (Peres, 2008), desde as primeiras culturas humanas, as normas morais na gestão do recurso, procurou assegurar uma partilha mínima que garantisse a sobrevivência (Galizoni e Ribeiro, 2011).

Durante milênios da evolução humana a responsabilidade moral diante da natureza assegurava que a água fosse valorizada pelo seu papel biológico e ecológico, e não pela comodidade. Justamente, a visão mecanicista, consequência das Guerras Mundiais, e do desenvolvimento tecnológico, afastou os valores éticos e morais da gestão dos recursos naturais. Com isto, estabeleceu-se uma crise entre os interesses do capitalismo e as necessidades homeostáticas do ambiente, levando à privatização dos serviços que asseguram acesso ao recurso nos momentos de diminuição da demanda (Singh, 1992). Desde então, a crise hídrica vem sendo pensada como um problema de ordem técnica e não ética, reduzindo a questão à esfera do conhecimento tecnocientífico, distanciando-a, desse modo, das questões morais e ambientais (Yazdanpanah et al., 2013b).

A mudança de uma visão antropocêntrica para uma percepção ecocêntrica é apontada como fundamental por autores como Reseane (2010), Tvedt (2014) e Yazdanpanah et al., (2013a), pois a natureza não pode mais ser concebida como um elemento separado da sociedade. Para Selborne (2001) a administração hídrica deve convergir para um equilíbrio ético do uso da água, e para uma mudança no papel do homem na preservação do planeta, de modo que o mesmo possa sentir-se pertencente e corresponsável à vida na biosfera através da aplicação de seis princípios éticos:

Princípio da dignidade humana, relacionado com a impossibilidade de existir vida sem água;

Princípio da participação, especialmente os vulneráveis precisam estar envolvidos no planejamento e na distribuição da água;

Princípio da solidariedade, pois a partir do momento que se tem a consciência da igualdade entre as pessoas na necessidade da água, a administração integrada pode ser vista como consequência direta;

Princípio da igualdade humana, abrangendo a concepção de que a concessão deve beneficiar a todos;

Princípio do bem comum, pois, como um bem de todos, caso não seja administrada adequadamente, pode comprometer a dignidade e o potencial humano; e

Princípio da economia, que visa o respeito pela criação e precaução no uso prudente.

O acesso a água é um direito humano (Clark et al., 2012) e por isso, deve ser intermediado por normatizações políticas que protejam as pessoas de abusos legais, sociais e políticos. A restrição de acesso viola claramente os princípios éticos do respeito, beneficência, não maleficência e justiça.

Pontes (2003) ressalta que do ponto de vista da ética aplicada deve-se estimular uma reflexão quanto à relação estabelecida entre prestadores de serviços e população, a qual deve ser promovida e intermediada pelo Estado. Ahlert (2013), fazendo uso da teoria da ação comunicativa de Habermas (1989), destaca que para viabilizar o direito humano ao acesso à água potável, é necessário estimular uma ética de conhecimentos compartilhados e dialogados entre os diferentes atores sociais, pois não é possível alguém cuidar daquilo que não conhece, e preservar sem desenvolver o sentido da preservação.

Embora a percepção ética possa variar entre indivíduos, sociedades e países, a proteção da água demanda a compreensão dos aspectos ambientais, econômicos, sociais, geográficos, 
éticos e políticos (Datta, 2015; Browning-Aiken et al., 2014, Castro, 2007). Nesse sentido, quanto mais às decisões forem balizadas por valores morais frutos da reflexão coletiva, tais como honestidade, verdade e lealdade, menos esforços serão necessários com políticas públicas e com normatizações para evitar a exploração oportunista, e práticas corruptas que prejudicam o bem-estar dos cidadãos e da natureza.

\section{CONCLUSÃO}

Os dados do presente estudo ilustram que o limitado interesse do meio científico em discutir aspectos éticos relacionados com a crise hídrica, impossibilita a identificação dos grupos vulneráveis, mesmo em um segmento para o qual é atribuída grande responsabilidade na geração e na mitigação do problema, como no meio rural, onde se utiliza grande parte do recurso hídrico, para produzir e manter as relações comerciais e industriais, que envolvem a cadeia produtiva agrícola e pecuária no Brasil. Neste contexto é de fundamental importância a identificação dos agentes e pacientes morais e as vulnerabilidades relacionadas à crise hídrica, para que seja possível avançar em busca de uma solução consensual e justa para este problema complexo e global.

Embora a sociedade tenha o entendimento de que a água é um recurso finito e que a sua falta compromete a continuidade da vida humana e do planeta, esse entendimento não sido suficiente para ampliar o grau de consciência quanto ao uso e do desperdício.

Segundo a reflexão de Targa e Batista (2015), apesar das melhorias que ocorreram no abastecimento de água, esgoto, energia, produção e disponibilidade de alimentos nas últimas duas décadas, o uso irresponsável individual, coletivo e da gestão do meio, trará implicações talvez irreversíveis, pois têm ocorrido em detrimento da abertura de novas áreas, com o desmatamento das florestas, erosão e esgotamento do solo, com a consequente sedimentação dos rios e degradação das fontes de água subterrâneas.

O Papa Francisco ao criticar a mercantilização da água em sua Encíclica "Laudato Si" afirma que deve ser feito um esforço para conscientizar a humanidade da necessidade de mudar o seu estilo de vida, sua produção e seu consumo, e de responsabilizar as políticas públicas e as grandes corporações pelos novos desafios mundiais, pois "não há duas crises separadas: uma ambiental e outra social, mas uma única e complexa crise socioambiental" (Papa Francisco, 2015).

Embora diferentes segmentos sociais tenham se mobilizado em buscar saídas para a crise hídrica, a complexidade e a amplitude que envolve a questão, faz com que estes resultados sejam quase que imperceptíveis, de modo que iniciativas pontuais ou individuais, embora louváveis, não contribuam para a solução do problema, pois é necessário de fato uma mudança paradigmática que balize a formação do cidadão global.

Neste sentido, entende-se que a bioética ambiental representa um instrumento de promoção de diálogo e de reflexão da sociedade, que viabiliza questionar os princípios e valores praticados no atual modelo de desenvolvimento, que nesta situação específica se materializa na questão da crise hídrica, mas que pode se manifestar em tantas outras situações como clima, poluição ou fome.

A essência inter e transdisciplinar da bioética torna a capaz de reunir em torno do mesmo debate tanto aqueles que assumem o papel de agentes morais, provenientes das ciências, da sociedade, da política, dos poderes públicos, como também os próprios vulneráveis ou pacientes morais, com seus saberes solidamente consolidados. Esta estratégia de equalizar os diálogos fará com que se eliminem as divergências entre as demandas do homem com as demandas da natureza, na medida em que a água além de ser um bem comum, e um direito humano, ela também revela um modo de interação com a natureza. A busca desse entendimento permitirá orientar as decisões que visem o bem-estar de todos os seres vivos 
desta e das futuras gerações.

\section{AGRADECIMENTOS}

Ao Programa de Pós-Graduação em Bioética da PUCPR.

\section{REFERÊNCIAS}

ABERS, R. N. R. M.; FORMIGA-JOHNSSON, B. F. M. E.; KECK, M. C. L. Inclusão, deliberação e controle: três dimensões democracia nos comitês e consórcios de bacias hidrográficas no Brasil. Ambiente \& Sociedade, v. 12, n. 1, p. 115-132, 2009. http://dx.doi.org/10.1590/S1414-753X2009000100009

AGORAMOORTHY, G. David Groenfeldt: Water ethics: A values approach to solving the water crisis. Water Resources Management, v. 28, n. 6, p. 1481-1483, 2014. http://dx.doi.org/10.1007/s11269-014-0575-5

AHLERT, A. Ação comunicativa e ética no acesso e uso sustentável da água: a experiência do saneamento rural de Marechal Cândido Rondon - Paraná. Horizonte, ano 11, n. 32, p. 1571-1588, 2013. http://dx.doi.org/10.5752/P.2175-5841.2013v11n32p1571

AUGUSTO, L. G. S.; GURGEL, I. G. D.; CAMARA-NETO, H. F. et al. O contexto global e nacional frente aos desafios do acesso adequado à água para consumo humano. Ciência e Saúde Coletiva, ano 6, n. 176, p.1511-1522, 2012. http://dx.doi.org/10.1590/S141381232012000600015

BAKKER, K. Liquid Assets. Alternatives, v. 29, n. 2, p. 17-21, 2003.

BARDIN, L. Análise do conteúdo. São Paulo: Edições 70, 2011. 280 p.

BERRY, K. A. Beyond the water crisis? Moving water and people away from the margins, Yearbook of the association of pacific coast geographers, v. 70, p. 14-27, 2008.

BOGLE, S. Just Water: theology, ethics, and the global water crisis. International journal of public theology, ano 3, n. 9, p. 379-381, 2015.

BROWNING-AIKEN, A.; SILVA, M. M. C.; FERNANDES NETO, J. F. N. et al. Avaliando o papel da aprendizagem socioecológica em governança participativa: construindo resiliência em seis comitês de bacias hidrográficas brasileiras. Desenvolvimento e Meio Ambiente, v. 30, p. 59-71, 2014. http://dx.doi.org/10.5380/dma.v30i0.33988

CASTRO, J. E. Watergovernance in thetwentieth-firstcentury. Ambiente \& Sociedade, v. 10, n. 2, p. 97-118, 2007. http://dx.doi.org/10.1590/S1414-753X2007000200007

CHAMBERLAIN, G. Troubled Waters: religion, ethics, and the global water crisis. Washington: Rowman \& Littlefield Publishers, 2008. 240p.

CHINNASAMY, P.; AGORAMOORTHY, G. Groundwater storage and depletion trends in tamilnadu state. Water Resources Management, v. 29, n. 7, p. 2139-2152, 2015. http://dx.doi.org/10.1007/s11269-015-0932-z

CHIODI, R. E.; SARCINELlE, O.; UEZU, A. Gestão dos recursos hídricos na área do Sistema Produtor de Água Cantareira: um olhar para o contexto rural. Revista Ambiente \& Água, v. 8, n. 3, p. 151-165, 2013. http://dx.doi.org/10.4136/ambiagua. 1162 
CHRISTOFIDIS, D. Água, ética, segurança alimentar e sustentabilidade ambiental. Bahia Análise \& Dados, v. 13, n. esp., p. 371-382, 2003.

CLARK, P. A.; PINEDP, C. A.; FADUS, M. et al. Slow-sand water filter: design, implementation, accessibility and sustainability in developing countries. Medical Science Monitor, ano 7, v. 18, p. 105-117, 2012.

http://dx.doi.org/10.12659\%2FMSM.883200

DATTA, P. S. Ethics to protect groundwater from depletion in India. Geological Society, v. 419, 2015. http://dx.doi.org/10.1144/SP419.1

DE-LA-TORRE-UGARTE-GUANILO, M. C.; TAKAHASHI, R. F.; BERTOLOZZI, M. R. Revisão sistemática: noções gerais. Revista da Escola de Enfermagem USP, v. 45, n. 5, p. 1260-1266, 2011. http://dx.doi.org/10.1590/S0080-62342011000500033

EMPINOTTI, V. L.; JACOBI, P. R. Novas práticas de governança da água? O uso da pegada hídrica e a transformação das relações entre o setor privado, organizações ambientais e agências internacionais de desenvolvimento. Desenvolvimento e Meio Ambiente, v. 27, p. 23-36, 2013. http://dx.doi.org/10.5380/dma.v27i0.27928

ESHEL, G.; SHEPON, A.; MAKOV, T. et al. Land, irrigation water, greenhouse gas, and reactive nitrogen burdens of meat, eggs, and dairy production in the United States. PNAS, ano 33, v. 111, p. 11996-12001, 2014. http://dx.doi.org/10.1073/pnas.1402183111

FIALA, A. Nero's fiddle: On hope, despair, and the ecological crisis. Ethics \& The environment, v. 15, n. 1, p. 51-68, 2010.

FINKLER, N. R.; MENDES, L. A.; BORTOLIN, T. A. et al. Cobrança pelo uso da água no Brasil: uma revisão metodológica. Desenvolvimento e Meio Ambiente, v. 33, p. 33-49, 2015. http://dx.doi.org/10.5380/dma.v33i0.36413

FOLTZ, R. C. Iran's water crisis: cultural, political, and ethical dimensions. Journal of Agricultural and Environmental Ethics, ano 4, n. 15, p. 357-380, 2002. http://dx.doi.org/10.1023/A:1021268621490

FREYFOGLE, E. T. Water rights and the common wealth. Environmental Law, v. 26, p. $27-$ $51,1996$.

GALIZONI, F. M.; RIBEIRO, E. M. Bem comum e normas costumeiras: a ética das águas em comunidades rurais de Minas Gerais. Ambiente \& Sociedade, v. 14, n. , p. 77-94; 2011. http://dx.doi.org/10.1590/S1414-753X2011000100005

GILL, S. Global crises and the crisis of global leadership. Cambridge: Cambridge University Press, 2012. 299p.

GUTIÉRREZ-MALAXECHEBARRÍA, A. M. Formal and informal irrigation in the Andean Countries. An Overview. Cuadernos de Desarrollo Rural, v. 74, n.11, p. 75-99, 2014. http://dx.doi.org/10.11144/Javeriana.CRD11-74.fiac

HABERMAS, J. Consciência moral e agir comunicativo. Rio de Janeiro: Tempo Brasileiro, 1989. 240p.

JÉQUIER, E.; CONSTANT, F. Water as an essential nutrient: the physiological basis of hydration. European Journal of clinical nutrition, v. 64, p. 115-23, 2010. http://dx.doi.org/10.1038/ejcn.2009.111 
JONAS, H. O princípio responsabilidade: ensaio de uma ética para a civilização tecnológica. Rio de Janeiro: Contraponto; Ed. PUC-RJ, 2006. 354 p.

LIMA, T. C. A. L.; CABRAL, A. C. A.; PESSOA, M. N. M. et al. A institucionalização das práticas de responsabilidade social: um estudo da companhia de água e esgoto do Ceará. Contextus - Revista Contemporânea de Economia e Gestão, ano 1, n. 9, p. 79-95, 2011.

MADANI, K. Water management in Iran: what is causing the looming crisis? Journal of environmental studies and sciences, v. 4, p. 315-328, 2014. http://dx.doi.org/10.1007/s13412-014-0182-z

MEDINA, E. U.; PAILAQUILÉN, R. M. B. A revisão sistemática e a sua relação com a prática baseada na evidência em saúde. Revista Latino-Americana de Enfermagem, v. 18, n. 4, p. 1-8, 2010. http://dx.doi.org/10.1590/S0104-11692010000400023

ORGANIZAÇÃO DAS NAÕES UNIDAS - ONU. O futuro que queremos. Rio de Janeiro, 2012. Disponível em: http://www.onu.org.br/rio20/agua.pdf. Acesso em: 03 mar. 2016.

PAPA FRANCISCO. Laudato Si - Louvado sejas: sobre o cuidado da casa comum. São Paulo: Editora Paulus; Loyola, 2015. 141p.

PERES, J. E. C. Los bienes comunes: sentidos procudcios sobre el agua em el Valle de Quibor na Venezuela. Espacio Abierto Cuaderno Venezolano, ano 17, n. 109, 2008.

PONTES, C. A. A. Urbe água e vida. Ética da proteção aplicada ao estudo de implicações morais no acesso desigual à água potável. 2003. 105f. Tese (Doutorado em Saúde Pública) - Escola Nacional de Saúde Pública, Fundação Oswaldo Cruz, Rio de Janeiro, 2003.

POTTER, V. R. Fragmented ethics and "bridge bioethics". Hastings Center Report, v. 29, p. 38-40, 1999. http://dx.doi.org/10.2307/3528538

PURDY, J. The politics of nature: climate change, environmental law, and democracy. Yale Law Journal, v. 119, p. 1122-1361, 2009.

RAHIMI, S.; ROODPOSHTI, M. S.; ABBASPOUR, R. A.Using combined AHP-genetic algorithm in artificial groundwater recharge site selection of Gareh Bygone Plain, Iran. Environmental Earth Sciences, ano 6, n. 72, p.1979-1992, 2014. http://dx.doi.org/10.1007/s12665-014-3109-9

REN, J. L.; LYU, P. H.; WU, X. M. et al. An informetric profile of water resources management literatures. Water resources management, v. 27, n. 13, p. 4679-4696, 2013. http://dx.doi.org/10.1007/s11269-013-0435-8

RESEANE, T. The theological responses to the socio-economic activities that undermine water as a resource. Original Research, v. 66, p. 1-7, 2010.

SALDI, L.; PETZ, I. Aguas ajenas, tierras extrañas. Desigualdad hídrica al sur de la cordillera de los Andes en Mendoza (Argentina) a principios del siglo XXI. Cuadernos de Desarrollo Rural, v. 75, p. 123-144, 2015.

SCHMIDT, J. J. Water management and the procedural turn: norms and transitions in Alberta. Water Resources Management, v. 28, n. 4, p. 1127-1141, 2014. http://dx.doi.org/10.1007/s11269-014-0544-z 
SELBORNE, L. A ética do uso da água doce: um levantamento. Brasília: Unesco, 2001. $80 \mathrm{p}$.

SINGH, R. P. B. Nature and cosmic integrity: a search in hindu geographical thought. The Geo Journal, ano 2, v. 26, p.139-147, 1992. http://dx.doi.org/10.1007/BF00241208

TARGA, M. S.; BATISTA, G. T. Benefits and legacy of the water crisis in Brazil. Revista Ambiente \& Água, v. 10, n. 2, 2015. http://dx.doi.org/10.4136/ambi-agua.1629

TVEDT, T. A journey in the future of water. London: IB Tauris, 2014. 262p.

UNITED NATIONS EDUCATIONAL, SCIENTIFIC AND CULTURAL ORGANIZATION - UNESCO. Water for a sustainable world. Paris, 2015. Disponível em: http://unesdoc.unesco.org/images/0023/002318/231823E.pdf. Acesso em: 3 mar. 2016.

YAZDANPANAH, M.; HAYATI, D.; ZAMANI, G. H. et al. Water management from tradition to second modernity: an analysis of the water crisis in Iran. Environment, Development and Sustainability, v. 15, n. 6, p. 1605-1621, $2013 \mathrm{a}$. http://dx.doi.org/10.1007/s10668-013-9452-2

YAZDANPANAH, M.; THOMPSON, M.; HAYATI, D. et al. A new enemy at the gate: Tackling Iran's water super-crisis by way of a transition from government to governance. Progress in Development Studies, ano 3, n. 13, p. 177-194, 2013 b.

YUAN, X.; JI, B.; TIAN, H. et al. Multiscaling analysis of monthly runoff series using Improved MF-DFA. Water Resources Management, v. 28, n. 12, p. 3891-3903, 2014. http://dx.doi.org/10.1007/s11269-014-0715-y 